\title{
Distribution, Pathotypes, and Metalaxyl Sensitivity of Phytophthora sojae from Heilongjiang and Fujian Provinces in China
}

\author{
Linkai Cui, Department of Plant Pathology, Nanjing Agricultural University, Nanjing 210095, China, and Forestry \\ College, Henan University of Science and Technology, Luoyang 471003, China; and Weixiao Yin, Qinghua Tang, \\ Suomeng Dong, Xiaobo Zheng, Zhengguang Zhang, and Yuanchao Wang, Department of Plant Pathology, Nan- \\ jing Agricultural University, China
}

\begin{abstract}
Cui, L., Yin, W., Tang, Q., Dong, S., Zheng, X., Zhang, Z., and Wang, Y. 2010. Distribution, pathotypes, and metalaxyl sensitivity of Phytophthora sojae from Heilongjiang and Fujian provinces in China. Plant Dis. 94:881-884.

Phytophthora sojae causes root and stem rot, one of the most devastating diseases of soybean worldwide. In Heilongjiang and Fujian provinces in China, serious cases of Phytophthora stem and root rot have occurred and caused heavy losses in the past several years. To determine the current population status of this pathogen, we investigated the pathogen's distribution, pathotypes, and metalaxyl sensitivity in both provinces. $P$. sojae was baited and isolated from 258 soil samples in both provinces using the soybean leaf bait method. The pathotypes of all isolates were characterized on 13 differential soybean cultivars using the hypocotyl slit inoculation method, and the sensitivity of all isolates to metalaxyl was tested in vitro. In all, 75 isolates were recovered from 75 fields in 33 counties; of these, 31 counties were in Heilongiiang Province and 2 counties were in Fujian Province. Thirty-five new pathotypes were identified compared with the previously defined races. Less than $5 \%$ of the isolates were virulent to cultivars with individual Rps genes 1a, 1c, or 1k. No metalaxyl-resistant isolates were found; the half maximal effective concentration values of all isolates ranged from 0.04 to $0.22 \mu \mathrm{g} \mathrm{ml} \mathrm{m}^{-1}$. These results suggest that effective management of the disease in both provinces can be accomplished through the use of resistant cultivars with Rps genes 1a ,1c, or 1k and the fungicide metalaxyl.
\end{abstract}

Phytophthora sojae Kaufm. \& Gerd. is an oomycete pathogen of soybean, classified in the kingdom Stramenopila. $P$. sojae causes damping-off of soybean seedlings and root rot of established plants, referred to as Phytophthora stem and root rot of soybean. It is a devastating disease of soybean that occurs throughout the United States and around the world (24). This disease causes approximately $\$ 1$ to 2 billion in annual agricultural losses (22). P. sojae has a narrow host range and is restricted primarily to soybean. It can spread out as oospores carried in soybean seed as well as oospores in soil and diseased residues. The occurrence of this disease is commonly associated with high soil moisture during the growing season. Host resistance, soil drainage control, and fungicidal seed treatments such as metalaxyl are generally used to manage the disease (16) but resistant cultivars have been the cornerstone for management of Phytophthora stem and root rot.

Corresponding author: Y. C. Wang

E-mail: wangyc@njau.edu.cn

Accepted for publication 13 March 2010.

doi:10.1094/PDIS-94-7-0881

(C) 2010 The American Phytopathological Society
Phytophthora stem and root rot of soybean is controlled mainly through the incorporation of race-specific resistant genes into soybean cultivars. However, P. sojae has been shown to be highly diverse in virulence and to adapt to changing deployment of Rps genes (14). Thus, monitoring the race or virulence structure of $P$. sojae populations is a key step in the management program for Phytophthora stem and root rot. $P$. sojae isolates are characterized to race based on soybean host differential reactions after inoculation via a hypocotyl inoculation method. Approximately 55 different races have been defined based on eight differentials $(3,5)$ but many new pathotypes that have not been assigned a race number have been reported in recent studies $(7,13,14)$.

In China, $P$. sojae was first isolated in 1989 (18). This pathogen has been under quarantine and currently is distributed in Heilongjiang and Fujian provinces $(2,23)$. A limited number of studies has been conducted on distribution of this pathogen, because $P$. sojae was discovered recently and Phytophthora stem and root rot didn't cause serious losses in 1990s. However, an increase in this disease's occurrence has been a trend in recent years. A 3-year investigation (2001 to 2004) showed that serious cases of the disease occurred in five locations (Huanan, Linbu, Qitaihe, Jiamusi, and Longhai) from the two prov- inces where majority of soybean plants were killed (23).

Soybean (Glycine max (L.) Merr.), which originated in China, is an important oilseed and food crop in China, with annual planting area larger than 9,000,000 ha. Phytophthora stem and root rot has become a major threat to soybean production in both Heilongjiang and Fujian Provinces. This research was initiated to control the disease effectively and safeguard future soybean production. The objectives were to determine the distribution, pathotypes, and metalaxyl sensitivity of $P$. sojae in both provinces.

\section{MATERIALS AND METHODS}

Soil sampling. Soil samples were collected from 258 soybean fields from Heilongjiang and Fujian Provinces during the 2007 growing season. The approximate size of a typical field was 2 acres. Fields were identified for sampling based on the presence of stem-rotting symptoms of Phytophthora stem and root rot, or lowlying areas where the soil is poorly drained after rain. The volume of a sample was 200 to $300 \mathrm{~cm}^{3}$. At least five individual samples were taken arbitrarily to a depth of 15 $\mathrm{cm}$ using a hand trowel from each field, and samples were well mixed to represent a single composite sample for each field, with a final volume of approximately 100 $\mathrm{cm}^{3}$. All soil samples were air dried, triturated, and then stored in paper pockets at room temperature.

Baiting and isolation. $P$. sojae was isolated from soil by modification of the soybean leaf baiting method (17). Soybean field soil $(10 \mathrm{~g})$ was moistened in a petri dish $(9 \mathrm{~cm}$ in diameter), preincubated in the light at $25^{\circ} \mathrm{C}$ for a week, then flooded with $25 \mathrm{ml}$ of sterile distilled water. Twenty leaf disks (10 $\mathrm{mm}$ in diameter), freshly cut with a paper punch from the unifoliolates of 10-day-old Williams soybean seedlings were floated immediately on the surface of the water. After $12 \mathrm{~h}$, the floating leaf disks were removed, washed, and placed in another petri dish with $25 \mathrm{ml}$ of sterile distilled water. Sporangia emerging from the edge of the infected leaf discs were observed under stereomicroscopy after $48 \mathrm{~h}$ of incubation in the water.

Leaf discs with sporangia of $P$. sojae were placed in another petri dish $(6 \mathrm{~cm}$ in diameter) with $10 \mathrm{ml}$ of sterile distilled 
water. The entire set of petri dishes was placed in a refrigerator at $4^{\circ} \mathrm{C}$ for $30 \mathrm{~min}$ and then placed back at $25^{\circ} \mathrm{C}$ for $1 \mathrm{~h}$ to complete the process of zoospore release. Zoospore solution was spread on $1.5 \%$ water agar containing pentachloronitrobenzene at $25 \mu \mathrm{g} \mathrm{m}{ }^{-1}$, carbendazim at $25 \mu \mathrm{g}$ $\mathrm{ml}^{-1}$, rifampicin at $20 \mu \mathrm{g} \mathrm{ml}^{-1}$, and ampicillin at $50 \mu \mathrm{g} \mathrm{m} \mathrm{m}^{-1}$ and $12 \mathrm{~h}$ later the germinated zoospores were isolated and pure cultures were obtained. Cultures were stored on V8 juice agar (10\% V8 juice filtered through four layers of cheesecloth, $1 \% \mathrm{CaCO}_{3}$, and $1.5 \%$ agar) at $12^{\circ} \mathrm{C}$. The baiting process was repeated once for soil samples that did not yield $P$. sojae in the initial baiting attempt. All cultures were compared with a known culture of race 2 (from B. M. Tyler, Virginia Bioinformatics Institute) and examined carefully for hyphae, colony, sporangium, and oospore morphology (9) to verify that isolates were $P$. sojae.

Pathotype evaluation. Pathotypes of $P$. sojae were determined using the hypocotyl slit inoculation method (10) on differential cultivars carrying the 13 standard Rps genes that have been used to characterize virulence $(1,3,8)$. The differential cultivars (from B. M. Tyler, Virginia Bioinformatics Institute) were Harlon (Rps1a), L77-1863 (Rps1b), Williams79 (Rps1c), PI103091 (Rps1d), Williams82 (Rps1k), L76-1988 (Rps2), Chapman (Rps3a), PRX146-36 (Rps3b), PRX145-48 (Rps3c), L85-2352 (Rps4), L85-3059 (Rps5), Harosoy62xx (Rps6), and Harosoy (Rps7). The universal susceptible cultivar was Williams.

Sets of 12 seeds of each of the differential cultivars were planted in 10-by-12-cm plastic pots containing vermiculite in the greenhouse. Inoculum was prepared by growing cultures of the isolates on V8 juice agar in the dark for a week. After having been thinned out, 10 7-day-old seedlings were inoculated. Immediately after inoculation, inoculated plants were maintained in high humidity and darkness at $25^{\circ} \mathrm{C}$ for $12 \mathrm{~h}$. Thereafter, inoculated plants were kept in the greenhouse at $25^{\circ} \mathrm{C}$
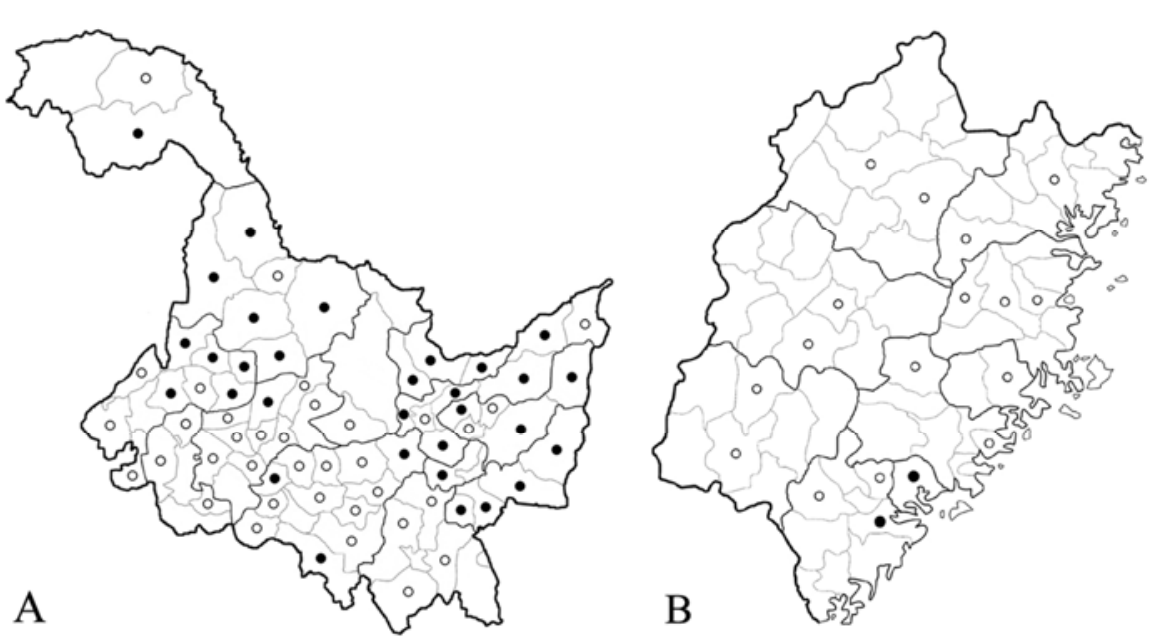

Fig. 1. Distribution of Phytophthora sojae in A, Heilongjiang and B, Fujian provinces. Circles repre-

sent counties sampled. Black circles represent counties where $P$. sojae was detected.

with a 14-h photoperiod and scored 5 days post inoculation as susceptible or resistant. Race 2 and an agar control were used as standard checks with all inoculation trials. Pathotype determination was repeated twice with each isolate. A differential was considered susceptible if $60 \%$ or more of the seedlings were killed, resistant if $40 \%$ or fewer of the seedlings were killed, and intermediate if 40 to $60 \%$ of the seedlings were killed $(8,13)$.

Metalaxyl sensitivity testing. Metalaxyl (technical grade; Jiangsu Baoling Chemical Co., Nantong, Jiangsu, China) was dissolved in dimethyl sulfoxide before adding it to medium. Stock cultures from the isolates were grown on V8 juice agar for 7 days in the dark. Based on the previous result, that all isolates were transferred to V8 juice agar previously amended with metalaxyl at $1 \mu \mathrm{g} \mathrm{ml}^{-1}$ and showed a very small mount of growth after 7 days, agar disks ( $5 \mathrm{~mm}$ in diameter) were removed from actively growing margins of the cultures and transferred to V8 juice agar previously amended with metalaxyl at $0,0.01$, $0.05,0.1,0.5$, and $1 \mu \mathrm{g} \mathrm{ml}^{-1}$. Three replicate petri dishes were tested for each isolate. Isolate growth was determined by measuring colony diameters in two perpendicular directions after 7 days of incubation in the dark at $25^{\circ} \mathrm{C}$. Measurements were averaged, the diameter of the mycelial plug was subtracted, and relative growth reduction for each rate of fungicide was calculated as follows: [100 - (growth with fungicide/growth in control plate) $\times$ 100] $(19,20)$. The half maximal effective concentration $\left(\mathrm{EC}_{50}\right)$ value was estimated by plotting the percent inhibition against the log-scale of fungicide concentration. Two independent trials were conducted to determine $\mathrm{EC}_{50}$ values for each sensitivity test. The isolates were considered to be sensitive to metalaxyl if $\mathrm{EC}_{50}$ values were less than $1.0 \mu \mathrm{g} \mathrm{ml}^{-1}$, resistant if $\mathrm{EC}_{50}$ values were more than $100 \mu \mathrm{g} \mathrm{ml}^{-1}$, and intermediate if $\mathrm{EC}_{50}$ values ranged from 1.0 to $100 \mu \mathrm{g} \mathrm{ml}^{-1}(19,20)$.

\section{RESULTS}

Distribution of $\boldsymbol{P}$. sojae. $P$. sojae was recovered from 75 of 258 fields, and 75 isolates were obtained. All 75 isolates matched the features of $P$. sojae. Each of the 75 isolates came from a different field. In all, 57 isolates were isolated from $39 \%$ of soil samples in Heilongjiang Province while 18 isolates were isolated from $16 \%$ of soil samples in Fujian Province. These 75 fields were located in 33 of the 84 counties sampled (Fig. 1); of these, 31 counties were in Heilongjiang Province and 2 counties (Longhai and Xiamen) were in Fujian Province. The results indicated that $P$. sojae was distributed widely in Heilongjiang Province compared with the narrow distribution in Fujian Province.

Pathotype evaluation. All 75 isolates were characterized for pathotype on 13 differential cultivars. In total, 35 pathotypes were identified, which included 30 pathotypes from Heilongjiang Province and 7 pathotypes from Fujian Province; however, all pathotypes were not characterized to any race based on published race definitions (Table 1). Two virulence pathotypes $(2,3 a, 3 b, 3 c, 4,5,6,7$ and $2,3 a, 3 c, 4,5,6,7)$ were recovered from both provinces. In Heilongjiang Province, Each pathotype composed less than $11 \%$ of the isolates tested. In Fujian Province, the three common pathotypes identified, which composed $67 \%$ of the isolates tested, were the pathotypes with virulence phenotype $1 \mathrm{~b}, 2,4,5$ (28\%), 2,3a,3c,4,5,6,7 (22\%), and $2,3 \mathrm{a}, 4,5,6,7(17 \%)$.

Virulence frequency to 13 soybean differentials were different in the two provinces. In Heilongjiang Province, only 2, 4,4 , and $2 \%$ of the isolates were virulent to cultivars with single Rps genes $1 \mathrm{a}, 1 \mathrm{~b}$, $1 \mathrm{c}$, and $1 \mathrm{k}$, respectively, whereas 93 and $91 \%$ of the isolates were virulent to cultivars with single Rps genes 2 and 3c, respectively (Fig. 2). In Fujian Province, no isolates were able to overcome Rps genes $1 \mathrm{a}, 1 \mathrm{c}, 1 \mathrm{~d}$, and $1 \mathrm{k}$, whereas all isolates were able to overcome Rps genes 4 and 5 (Fig. 2).

Metalaxyl sensitivity testing. $\mathrm{EC}_{50}$ values of all 75 isolates ranged from 0.04 to $0.22 \mu \mathrm{g} \mathrm{ml}^{-1}$, and the mean $\mathrm{EC}_{50}$ value was $0.1 \mu \mathrm{g} \mathrm{ml}^{-1}$. $\mathrm{EC}_{50}$ values of more than $80 \%$ of all isolates ranged from 0.06 to $0.15 \mu \mathrm{g}$ $\mathrm{ml}^{-1}$ (Fig. 3). Therefore, all isolates were sensitive to metalaxyl. However, resistance of the population in Heilongjiang Province to metalaxyl was higher than that of the population in Fujian Province. The mean $\mathrm{EC}_{50}$ values of the population in Heilongjiang and Fujian Provinces were 0.11 and $0.08 \mu \mathrm{g} \mathrm{ml}^{-1}$, respectively.

\section{DISCUSSION}

The populations of $P$. sojae from Heilongjiang and Fujian Provinces in China were studied in detail, and three important results were provided. First, $P$. 
sojae was distributed widely in Heilongjiang Province compared with the narrow distribution in Fujian Province. Second, less than $5 \%$ of the isolates were able to overcome Rps genes $1 \mathrm{a}, 1 \mathrm{c}$, and $1 \mathrm{k}$ in both provinces. Third, all isolates from the two provinces were sensitive to metalaxyl. The combination of these results may provide theoretical guidance for the control of Phytophthora stem and root rot in the two provinces.

Because $P$. sojae was first isolated in northeast China in 1989, it has also been found in more than 20 counties in Heilongjiang Province $(12,25,26)$. In this study, the pathogen was isolated from 31 counties in Heilongjiang Province. Nine counties (Huma, Wuchang, Kedong, Keshan, Baiquan, Fuyu, Xunke, Wudalianchi, and Jidong) were first reported from which this pathogen was isolated. These results show that $P$. sojae was already widely distributed in Heilongjiang Province. Also, $P$. sojae was reportedly found in Longhai and Xiamen in Fujian Province several years ago (2). In this study, though we collected soil samples from many regions in Fujian Province and examined these samples carefully, $P$. sojae was still only isolated from samples in Longhai and Xiamen. It is evident that $P$. sojae was still limited to these areas and has not spread in the past several years. Strict quarantine measures were applied by local governments to prevent it from spreading to other areas but quarantine measures for this pathogen should further be strengthened in the areas.

It was previously reported that 10 known races (races 1, 3, 8, 9, 11, 13, 15, 17, 21, and 24) and some new pathotypes were identified in Heilongjiang Province using eight soybean differentials, whereas there are no reports about pathotype of $P$. sojae in Fujian Province $(12,25)$. In previous studies, race 1 was the dominant race in Heilongjiang Province. Although 35 pathotypes were identified in this study, they were not different from those of previous studies. We hypothesize that two main causes are responsible for the difference. First, the number of differential cultivars was increased from 8 to 13. In our study, we could find four known races (races 1, 13, 15, and 17) that were identified in previous studies if five extra differential cultivars were removed. Second, $P$. sojae was isolated from diseased soybean plants in previous studies. $P$. sojae with more pathotypes was not isolated because of the role of host selective pressure. Furthermore, few pathotypes were in accordance with those that were reported in foreign studies $(3,5,7,13,14)$. Two possible causes exist. First, after $P$. sojae was introduced into China, it has varied and new pathotypes have appeared under selective pressure of native soybean cultivars. Second, $P$. sojae was not introduced into China but was native in China.
Significantly, less than $5 \%$ of the collected isolates from both provinces could overcome Rps genes 1a, 1c, and 1k, indicating that soybean cultivars with Rps genes $1 \mathrm{a}, 1 \mathrm{c}$, or $1 \mathrm{k}$ can be more wildly grown in the two provinces to control Phytophthora stem and root rot. In the United States, Rps genes 1c and 1k were deployed in soybean cultivars in the 1990s. Not long after that, however, reports on the increasing percentage of isolates with virulence to soybeans containing Rps $1 \mathrm{c}$ and $1 \mathrm{k}$ began to surface $(3,13,15)$. This is because $P$. sojae is highly diverse in virulence and can adapt to changing deployment of Rps genes. Hence, we must monitor the virulence structure of the $P$. sojae population continuously and deploy appropriate Rps genes to control Phytophthora stem and root rot.

In 1993, 17 isolates of $P$. sojae from China were tested for sensitivity to

Table 1. Pathotypes of Phytophthora sojae baited from soybean field soils collected in Heilongjiang and Fujian provinces in 2007

\begin{tabular}{|c|c|c|c|c|}
\hline Number & Virulence pathotype $^{a}$ & Race $^{\mathbf{b}}$ & No. of isolates ${ }^{c}$ & Province $^{\mathrm{d}}$ \\
\hline 1 & $1 \mathrm{a}, 2,4,5,6$ & UD & 1 & Heilongjiang \\
\hline 2 & $1 \mathrm{~b}, 1 \mathrm{~d}, 2,3 \mathrm{a}, 6$ & UD & 1 & Heilongjiang \\
\hline 3 & $1 b, 1 d, 2,3 a, 3 b, 3 c, 4,5,6,7$ & UD & 1 & Heilongjiang \\
\hline 4 & $1 b, 2,4,5$ & UD & 5 & Fujian \\
\hline 5 & $1 b, 4,5$ & UD & 2 & Fujian \\
\hline 6 & $1 \mathrm{c}, 2,3 \mathrm{a}, 3 \mathrm{c}, 4,5,6,7$ & UD & 1 & Heilongjiang \\
\hline 7 & $1 \mathrm{c}, 2,3 \mathrm{~b}, 3 \mathrm{c}, 5,6$ & UD & 1 & Heilongjiang \\
\hline 8 & $1 d, 2,3 c$ & UD & 1 & Heilongjiang \\
\hline 9 & $1 \mathrm{~d}, 2,3 \mathrm{c}, 4,5,6$ & UD & 1 & Heilongjiang \\
\hline 10 & $1 d, 2,3 c, 4,5,6,7$ & UD & 1 & Heilongjiang \\
\hline 11 & $1 \mathrm{~d}, 4,5$ & UD & 1 & Heilongjiang \\
\hline 12 & $1 \mathrm{k}, 2,3 \mathrm{~b}, 3 \mathrm{c}, 4,5,6$ & UD & 1 & Heilongjiang \\
\hline 13 & $2,3 a, 3 b, 3 c, 4,5,6,7$ & UD & 3 & Combined \\
\hline 14 & $2,3 \mathrm{a}, 3 \mathrm{c}, 4,5$ & UD & 2 & Heilongjiang \\
\hline 15 & $2,3 \mathrm{a}, 3 \mathrm{c}, 4,5,6$ & UD & 4 & Heilongjiang \\
\hline 16 & $2,3 a, 3 c, 4,5,6,7$ & UD & 6 & Combined \\
\hline 17 & $2,3 a, 4,5,6,7$ & UD & 3 & Fujian \\
\hline 18 & $2,3 b, 3 c, 4,5,6$ & UD & 1 & Heilongjiang \\
\hline 19 & $2,3 b, 3 c, 4,5,6,7$ & UD & 3 & Heilongjiang \\
\hline 20 & $2,3 b, 3 c, 4,5,7$ & UD & 1 & Heilongjiang \\
\hline 21 & $2,3 \mathrm{c}$ & UD & 4 & Heilongjiang \\
\hline 22 & $2,3 \mathrm{c}, 4$ & UD & 1 & Heilongjiang \\
\hline 23 & $2,3 c, 4,5$ & UD & 6 & Heilongjiang \\
\hline 24 & $2,3 c, 4,5,6$ & UD & 5 & Heilongjiang \\
\hline 25 & $2,3 \mathrm{c}, 4,5,6,7$ & UD & 6 & Heilongjiang \\
\hline 26 & $2,3 \mathrm{c}, 4,6$ & UD & 1 & Heilongjiang \\
\hline 27 & $2,3 c, 5$ & UD & 2 & Heilongjiang \\
\hline 28 & $2,3 c, 5,6$ & UD & 2 & Heilongjiang \\
\hline 29 & $2,4,5$ & UD & 2 & Fujian \\
\hline 30 & 2,5 & UD & 1 & Heilongjiang \\
\hline 31 & 2,6 & UD & 1 & Heilongjiang \\
\hline 32 & $3 a, 3 c$ & UD & 1 & Heilongjiang \\
\hline 33 & $3 b, 3 c$ & UD & 1 & Heilongjiang \\
\hline 34 & $3 b, 3 c, 4,5$ & UD & 1 & Heilongjiang \\
\hline 35 & $4,5,7$ & UD & 1 & Fujian \\
\hline
\end{tabular}

a Virulence pathotype, which is a list of ineffective Rps genes among 13 soybean Rps gene differentials (1a, 1b, 1c, 1d, 1k, 2, 3a, 3b, 3c,4, 5, 6, and 7).

${ }^{\mathrm{b}}$ Race as reported by Dorarance et al. (3) and Grau et al. (5). UD = undefined races of $P$. sojae.

c In total, 75 isolates were evaluated.

${ }^{\mathrm{d}}$ Province in which $P$. sojae was baited and isolated.

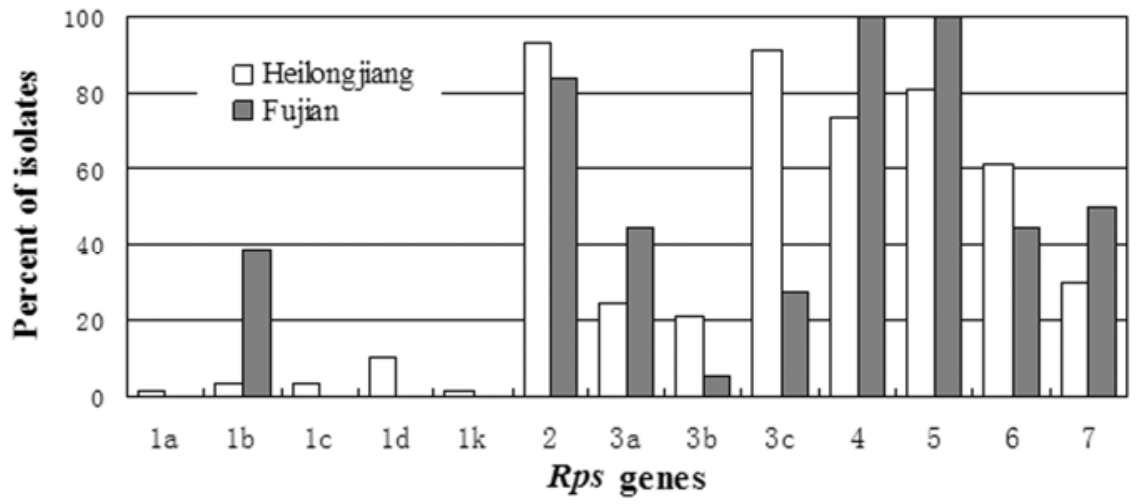

Fig. 2. Frequency of virulence of Phytophthora sojae isolates on individual Rps genes. 


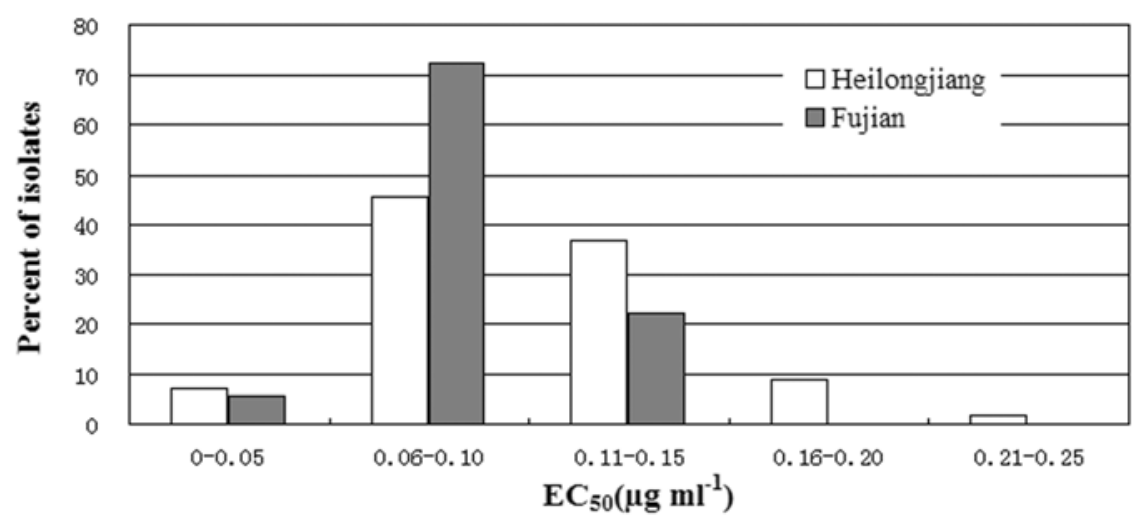

Fig. 3. Distribution of half maximal effective concentration $\left(\mathrm{EC}_{50}\right)$ values of Phytophthora sojae isolates for metalaxyl.

metalaxyl (11). At that time, the mean $\mathrm{EC}_{50}$ value of the population was $0.01 \mu \mathrm{g}$ $\mathrm{ml}^{-1}$ and all isolates were sensitive to metalaxyl. In our study presented here, the mean $\mathrm{EC}_{50}$ value of the $P$. sojae population was $0.1 \mu \mathrm{g} \mathrm{ml}^{-1}$. The results show that the resistance of the Chinese population to metalaxyl has increased in the last more than 10 years but also that the Chinese population of $P$. sojae remains sensitive to metalaxyl. Therefore, Phytophthora stem and root rot can be controlled effectively in China by metalaxyl and other compounds with the same modes of action. Metalaxyl resistance has been frequently detected in other Phytophthora spp. $(4,6,21)$ but the $P$. sojae population from China is still sensitive to metalaxyl, because local farmers have not realized the destructiveness of this disease and seldom use fungicides to control it. In the United States, Phytophthora stem and root rot is one of the most important soybean diseases and metalaxyl has been used to manage it since the mid-1980s. However, reports of metalaxyl-resistant isolates detected in soybean fields have not yet been published $(13,14)$. Resistance to metalaxyl in $P$. sojae has been difficult to produce, likely because only minor selection pressure was exerted on $P$. sojae by these compounds when they were used as seed treatments (14).

\section{ACKNOWLEDGMENTS}

We thank B. M. Tyler for supplying seed of differentials and $P$. sojae isolates. Funding was provided by the National Special Research Programs (Agriculture) for Non-Profit Trades (No. 320).

\section{LITERATURE CITED} M., Fioritto, R. J., and St-Martin, S. K. 2003. $R p s 8$, a new locus in soybean for resistance to Phytophthora sojae. Crop Sci. 43:101-105.

2. Chen, Q. H., Weng, Q. Y., Wang, Y. C., and Zheng, X. B. 2004. Identification and sequencing of ribosomal DNA-ITS of Phytophthora sojae in Fujian. Acta Phytopathol. Sin. 34:112116.

3. Dorrance, A. E., McClure, S. A., and deSilva, A. 2003. Pathogenic diversity of Phytophthora sojae in Ohio soybean fields. Plant Dis. 87:139-146.

4. Gisi, U., and Cohen, Y. 1996. Resistance to phenylamide fungicides: a case study with Phytophthora infestans involving mating type and race structure. Annu. Rev. Phytopathol. 34:549-572.

5. Grau, C. R., Dorrance, A. E., Russin, J., and Bond, J. 2004. Fungal diseases. Chapter 14 in: Soybeans: Improvement, Production, and Uses, third ed. no. 43. American Society of Agronomy, Madison, WI.

6. Hwang, J., and Benson, D. M. 2005. Identification, mefenoxam sensitivity, and compatibility type of Phytophthora spp. attacking floriculture crops in North Carolina. Plant Dis. 89:185-190.

7. Jackson, T. A., Kirkpatrick, T. L., and Rupe, J. C. 2004. Races of Phytophthora sojae in Arkansas soybean fields and their effects on commonly grown soybean cultivars. Plant Dis. 88:345-351.

8. Kaitany, R. C., Hart, L. P., and Safir, G. R. 2001. Virulence composition of Phytophthora sojae in Michigan. Plant Dis. 85:1103-1106.

9. Kauffmann, M. J., and Gerdemann, J. W. 1958. Root and stem rot of soybean caused by Phytophthora sojae n. sp. Phytopathology 48:201208.

10. Laviolette, F. A., and Athow, K. L. 1981. Physiologic races of Phytophthora megasperma f. sp. glycinea in Indiana, 1973-1979. Plant Dis. 65:884-885.

11. Li, B. D., Peng, Y. F., and Shen, C. Y. 1993. Sensitivity and variability of Phytophthora
1. Burnham, K. D., Dorrance, A. E., Francis, D. megasperma f. sp. glycinea to metalaxyl. Acta Phytopathol. Sin. 25: 23-27.

12. Ma, S. M., Ding, J. J., Zheng, T. Q., and Gu, X. 2005. The identification of physiological races of Phytophthora megasperma. Soybean Sci. 24:260-262.

13. Malvick, D. K., and Grunden, E. 2004. Traits of soybean-infecting Phytophthora populations from Illinois agricultural fields. Plant Dis. 88:1139-1145.

14. Nelson, B. D., Mallik, I., McEwen, D., and Christianson, T. 2008. Pathotypes, distribution, and metalaxyl sensitivity of Phytophthora sojae from North Dakota. Plant Dis. 92:10621066.

15. Niu, X. F., Yang, X. B., Lundeen, P., Uphoff, M. D., and Cianzio, S. R. 2003. Changes in Phytophthora sojae races in Iowa soybean fields. (Abstr.) Phytopathology 93:S66.

16. Schmitthenner, A. F. 1999. Phytophthora rot. In: Compendium of Soybean Diseases. G. L. Hartman, J. B. Sinclair, and J. C. Rupe, eds. American Phytopathological Society Press, St. Paul, MN.

17. Schmitthenner, A. F., Hobe, M., and Bhat, R. G. 1994. Phytophthora sojae races in Ohio over a 10-year interval. Plant Dis. 78:269-276.

18. Shen, C. Y., and Su, Y. C. 1991. Discovery and preliminary studies of Phytophthora megasperma on soybean in china. Acta Phytopathol. Sin. 21:298.

19. Taylor, R. J., Pasche, J. S., and Gudmestad, N. C. 2006. Biological significance of mefenoxam resistance in Phytophthora erythroseptica and its implications for the management of pink rot of potato. Plant Dis. 90:927934.

20. Taylor, R. J., Salas, B., Secor, G. A., Rivera, V., and Gudmestad, N. C. 2002. Sensitivity of North American isolates of Phytophthora erythroseptica and Pythium ultimum to mefenoxam (metalaxyl). Plant Dis. 86:797-802.

21. Timmer, L. W., Graham, J. H., and Zitko, S. E. 1998. Metalaxyl-resistant isolates of Phytophthora nicotianae: occurrence, sensitivity, and competitive parasitic ability on citrus. Plant Dis. 82:254-261.

22. Tyler, B. M. 2007. Phytophthora sojae: root rot pathogen of soybean and model oomycete. Mol. Plant Pathol. 8:1-8.

23. Wang, Z. Y., Wang, Y. C., Zhang, Z. G., and Zheng, X. B. 2006. Genetic relationships among Chinese and American isolates of Phytophthora sojae assessed by RAPD markers. Chin. Sci. Bull. 51:2095-2102.

24. Wrather, J.A., and Koenning, S.R. 2006. Estimates of disease effects on soybean yields in the United States 2003 to 2005. J. Nematol. 38:173-180.

25. Zhang, S. Z., Wu, J. J., Xu, P. F., and Li, W. B. 2008. Identification of virulence Phytophthora sojae in Heilongiiang province and the first report on race 15 in China. Chin. J. Oil Crop Sci. 30:229-234.

26. Zhu, Z. D., Wang, H. B., Wang, X. M., Chang, R. Z., and Wu, X. F. 2004. Distribution and virulence diversity of Phytophthora sojae in China. Agric. Sci. China 3:116-123. 